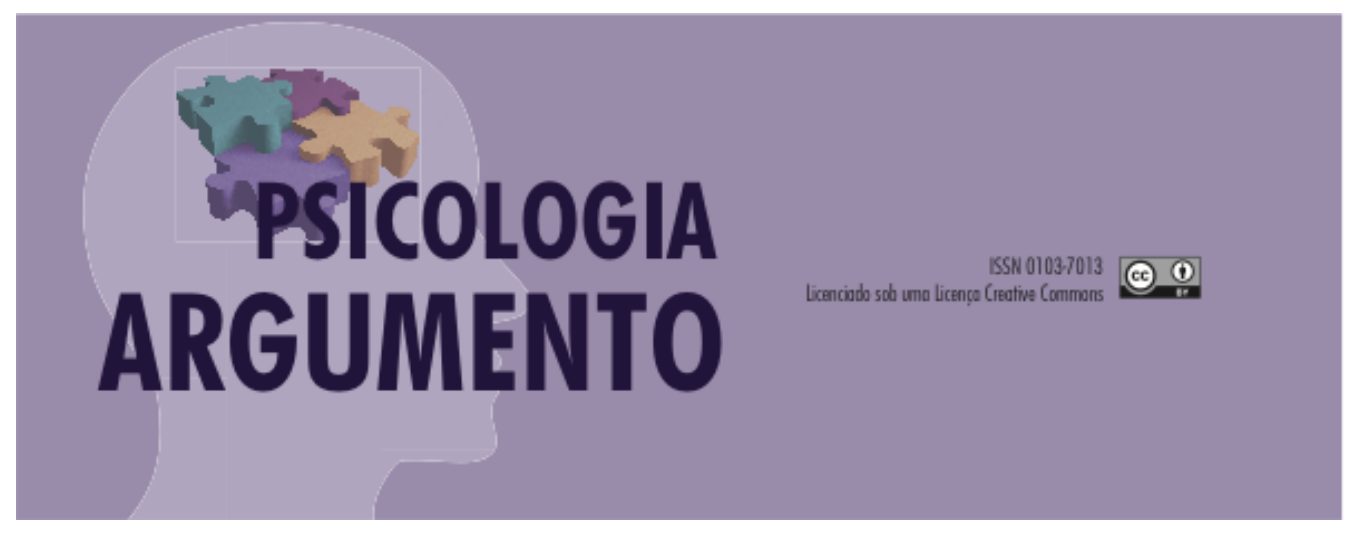

doi: 10.7213/psicol.argum.34.087.AO07

\title{
Alienação e separação: impasses da relação mãe e filha
}

\begin{abstract}
Alienation and separation: impasses of mother and daughter relationship
\end{abstract}
Fernanda Cristina Wandal dos Santos ${ }^{[\mathrm{a}]}$, Juliana Radaelli ${ }^{[\mathrm{b}]}$

\footnotetext{
${ }^{[a]}$ Pós-Graduação em Psicologia Clínica: abordagem psicanalítica pela Pontifícia Universidade Católica do Paraná (PUC/PR). Graduação em Psicologia pela Universidade Positivo (UP). Email: fernandawandal@hotmail.com.br

${ }^{[b]}$ Doutora em Educação pela Universidade de São Paulo (USP). Mestre em Educação pela Universidade de São Paulo (USP). Graduada em Psicologia pela Universidade Tuiuti do Paraná (UTP). Email: julianaradaelli74@gmail.com
}

\section{Resumo}

Este artigo objetiva abordar a alienação e a separação enquanto operações da relação entre mãe e filha, bem como os conflitos que a permeiam. À luz da psicanálise, utiliza-se revisão bibliográfica como metodologia para reunir conteúdos relativos à temática proposta. Analisam-se, paralelamente, fragmentos clínicos de duas pacientes para ilustrar o processo de distinção entre mãe e filha. Ademais, o conceito edipiano e o conceito de fantasia são retomados para possibilitar a interpretação dos recortes clínicos. Observa-se que o processo de singularização de mãe e filha não ocorre de maneira simples, tendo em vista que a filha recorre a uma invenção singular para lidar com o conflito de uma fantasia construída e responder à pergunta "O que o Outro materno quer de mim?".

Palavras-chave: Relação entre mãe e filha. Feminilidade. Complexo de Édipo. Fantasia. 


\begin{abstract}
This article aims to approach alienation and separation as operations of the relationship between mother and daughter as well as its conflicts. In light of psychoanalysis, a bibliographic review will be used to gather content related to the theme. In parallel, clinical fragments of two patients are analyzed to illustrate the process of distinction between mother and daugther. Additionally, the Oedipus complex and the concept of fantasy are used to interpret clinical extracts. It is observed that the process of singularization in the mother-daughter relationship does not occur in a simple manner, as the daughter resorts to a singular invention to cope with a conflict generated by a conflict and to respond to the question: "What does the maternal Other want from me?".
\end{abstract}

Keywords: Mother and daughter relationship. Femininity. Oedipus Complex. Fantasy.

\title{
Introdução
}

A relação entre mãe e filha tem sido uma temática recorrente no discurso de mulheres em análise, e Sigmund Freud, desde a criação da psicanálise, buscou estudar a importância dessa relação na vida das mulheres. Freud tinha a impressão de que jamais as entenderia se antes não valorizasse a relação da filha com a mãe. Lacan, também interessado em estudar esta questão, dizia que a mulher espera uma substância da mãe na posição de filha e de mulher, ou seja, a menina realmente parece esperar um algo a mais da mãe, menos do que espera de seu pai (LACAN, 1972, p.465).

Acerca da importância do estudo sobre o relacionamento entre mãe e filha, a clínica psicanalítica revela que este convívio configura-se como um fenômeno sobre o qual incidem várias facetas, fundamentando o amplo interesse dos psicanalistas pelo tema como objeto de pesquisa. Inclusive, foi a partir dos estudos de Freud que diversos autores realizaram novas leituras sobre a feminilidade e como a relação mãe-filha incide sobre esta. Zalcberg (2004), por exemplo, explica que a temática envolta no Complexo de Édipo inspirou novos conceitos que foram incorporados à obra psicanalítica.

Nota-se, na obra de Freud, a diferença essencial entre a constituição do sujeito homem e do sujeito mulher, pois ambos, a partir de certo momento, mudam seu curso de desenvolvimento e se constituem de maneiras diferentes. Em suas análises, Sigmund Freud (1931/2006) verificou que o desenvolvimento da mulher era mais complexo e continha mais detalhes do que o desenvolvimento do homem, algo constatado principalmente a partir da observação da relação entre mulher e mãe. Diante disso, torna-se relevante o estudo e a compreensão da relação mais arcaica que pode existir entre duas pessoas e os seus efeitos na vida de um sujeito - especialmente a filha, que, segundo Zalcberg (2004), tem maior dificuldade em fazer a separação da figura materna, buscando refúgio e baseando toda a sua vida nas experiências com a mãe. 
Santos, F. C. W., \& Radaelli, J.

Meninos e meninas traçam caminhos singulares para permanecerem ligados à mãe. Contudo, a menina encontra-se em uma posição reivindicadora do amor e do reconhecimento da mãe, experimentando uma condição de extrema passividade. Por consequência, a menina torna-se criadora de fantasias que a mantêm conectada ao vínculo materno, o que, em alguns momentos da vida, lhe causa sofrimento desmedido.

Isto posto, a partir das questões que envolvem a relação mãe-filha, duas perguntas norteiam o presente trabalho: Qual é a trajetória do período edípico? E o que se pode observar sobre a elaboração da fantasia que mantém a filha em uma posição reivindicadora em relação à mãe? Diante disto, objetiva-se também estudar a teoria do Complexo de Édipo e como este se desenvolve para o menino e para a menina, face ao processo de alienação e separação, bem como o conceito de fantasia para a psicanálise.

\section{Método}

\section{Participantes e Instrumento}

Metodologicamente, este trabalho adotou a pesquisa bibliográfica para reunir conteúdos relativos à temática proposta, como textos psicanalíticos de Freud a Lacan e outros estudiosos da área. Além disso, também foram selecionados fragmentos clínicos, originados da escuta clínica de pacientes em análise, caracterizando o presente trabalho como um estudo de caso em Psicanálise.

\section{Resultados e Discussões}

\section{A respeito do período pré-edipiano}

Em 1905, época em que Freud escreveu o texto Três ensaios sobre a teoria da sexualidade, $o$ autor compreendia que a mãe era o primeiro objeto de amor para o sexo masculino e feminino, não privilegiando em suas análises clínicas as relações entre mãe e filha. Mesmo no caso Dora, análise relatada por Freud (1901/2006) quando este já trabalhava com a concepção do primeiro objeto sexual para os dois sexos, o autor não se interessou em investigar exclusivamente a relação da jovem menina com a sua mãe, concentrando-se em compreender a relação fantasiosa da menina com o seu pai e os seus substitutos Sr. K. e o próprio Freud. Posteriormente Sigmund Freud pode rever os equívocos cometidos em sua análise de caso, percebendo que a relação de Dora com a mãe e a Sra. K era mais relevante. No entanto, não avançou na questão e nem supôs algo além de uma possí- 
vel tendência homossexual em Dora. Inclusive, algumas colocações de Freud não puderam ser desenvolvidas porque o autor entendia que a jovem estava no segundo tempo do Édipo, momento em que o objeto de amor da menina é o pai. O que Freud ainda não suspeitava na época da jovem Dora era que a menina já havia vivido uma relação bastante marcante e anterior ao Édipo.

A relação denominada pré-edipiana (FREUD, 1931/2006) é a fase de ligação exclusiva à mãe, na qual a criança encontra completude no ser materno e sustenta um sentimento de posse sobre este, acreditando ser aquilo que também completa a mãe. Diversos autores pós-freudianos contribuíram para o entendimento da teoria da relação mãe-criança. Zalcberg (2003) explica que a criança encontra-se em uma condição alienada ao mundo do desejo e das significações do Outro materno, ou seja, todas as experiências da vida da pequena criança só adquirem consistência se a mãe atribuir algum sentido a elas. Freud (1931/2006) também observava no comportamento das crianças a disposição de ser passiva ou ativa em relação à mãe. Por exemplo, ao passo que a criança recebe uma impressão ativa, ela tenta responder ativamente. A criança, então, transita por essas duas posições, ativa e passiva, com o intuito de dominar o mundo externo que lhe é apresentado. Na relação com a mãe, a criança tende a permanecer justamente em uma posição passiva, sendo cuidada, alimentada e vestida, coberta pelos cuidados maternos, mas sem deixar de direcionar ativamente sua sexualidade à mãe com o propósito de ser o que satisfaz esse Outro. Nesse momento, a criança está totalmente à disposição do Outro materno, conforme observado por Freud em seus estudos. Sequencialmente, o pesquisador procurou compreender como a menina se afasta da mãe e se direciona ao pai.

Até o momento da entrada do pai na selada relação entre mãe e criança, menino e menina estão se constituindo da mesma maneira, contudo, em certo momento do desenvolvimento infantil, a criança se depara com uma questão que mudará todo seu curso enquanto sujeito. Segundo Freud (1923/2006), durante o primeiro período da infância, a criança descobre a diferença entre homens e mulheres, ainda sem compreender a distinção dos órgãos genitais. Logo, ela atribui a ambos os sexos a presença de um órgão genital igual ao seu. Algo que proporciona efeitos simbólicos distintos quando a criança experimenta pela primeira vez a diferença sexual. Isso ocorre, segundo Freud, em meninos e meninas.

Freud (1924/2006) também compreende o Complexo de Édipo como a fase mais importante da primeira infância. Período em que o amor do pai e da mãe pelas crianças se apresenta como sentimento ilimitado e de posse, e que tende a terminar em desapontamento, visto que é impossível obter satisfação completa por meio desse amor. 
Santos, F. C. W., \& Radaelli, J.

\section{O Édipo no menino e na menina}

De acordo com Sigmund Freud (1923/2006), para o menino entre três ou quatro anos, meninas e meninos possuem o mesmo corpo. Com o tempo, levado pela curiosidade, o menino conclui que as meninas não possuem órgão genital comum ao seu. Ainda assim, na tentativa de encobrir esse fato, nega a distinção, dizendo, por exemplo, que o órgão da menina crescerá. $\mathrm{O}$ menino entende que existe o possuidor do órgão sexual masculino e um ser castrado - a mulher.

A partir do momento em que o pênis do menino vira um objeto valorizado por todos, o órgão passa a receber o nome de "falo". No entanto, Freud (1923/2006) esclarece em seus estudos que o falo não corresponde ao pênis, tratando-se de um ponto de referência para o sujeito, um ponto fantasiado e detentor do significado de força e ao mesmo tempo de vulnerabilidade. Visto isso, é no decorrer do desenvolvimento sexual da criança que acontece a fase fálica, o momento em que a criança acredita possuir o falo. Nessa fase as relações da criança com pai e a mãe se desenvolvem concomitantemente. Porém, os desejos sexuais fantasiosos do menino em relação à mãe tornam-se mais intensos, desenvolvendo catexia objetal por esta e caracterizando o pai como obstáculo entre o menino e a mãe (FREUD, 1923/2006).

Conforme concepção freudiana, o menino vivencia a ambivalência: o amor por um dos pais e o ódio e a hostilidade pelo outro. No Complexo de Édipo, o pai é visto como aquele que proíbe os desejos sexuais fantasiosos da criança, e a angústia de ser castrado é o que precipita o fim dessa fase para o menino. Então, tomado pelo sentimento de que poderia perder seu pênis-falo, o menino opta por proteger seu corpo e abandonar as catexias de objeto, ou seja, abandonar a mãe e substituir isso por identificações oferecidas pela figura paterna. Por conseguinte, o filho sai de um complexo demarcado pela angústia da castração, mas com uma identificação de caráter masculino.

Diferente do menino, a menina revolta-se quando reconhece a sua castração e a superioridade fantasiosa do homem em relação ao órgão sexual. Enquanto o menino teme a possibilidade da castração, a menina aceita o fenômeno como um fato consumado, pois compreende que em algum momento possuiu o órgão e depois o perdeu por castração (FREUD, 1924/2006). Isto posto, ainda conforme os estudos de Freud, verifica-se que para a menina a entrada no Complexo de Édipo é algo incompreensível. Em Sexualidade feminina (FREUD, 1931/2006), o autor demonstra sua intriga diante da questão feminina e seus mistérios. Freud pondera também sobre a entrada da menina e do menino no Complexo de Édipo, explicando que desde a fase pré-edipiana existe uma diferença entre ambos. A menina, no caso, vive a fase pré-edipiana de forma mais marcante, visto que é o período em que se inicia a construção da sua feminilidade. Segundo Zalcberg "a feminili- 
dade de uma filha constitui-se pré-edípica e edipicamente entre pai e mãe" (ZALCBERG, 2003, p. 14).

Precursor da psicanálise, Freud (1931/2006) procurou esclarecer como a menina substitui seu objeto de amor na infância ao renunciar a mãe como primeiro objeto de amor e voltar-se para o pai, ao contrário do menino. $\mathrm{O}$ autor presume que a fase primitiva da relação entre mãe e filha está relacionada à etiologia da histeria, pois é possível que exista certa dependência nessa relação, algo que muitas vezes se prolonga na vida adulta das mulheres. Sendo assim, é a partir da fase pré-edipiana que a menina elabora a pergunta que a acompanhará durante a vida: O que esse Outro materno quer de mim?

Como o menino, a menina também acredita que todos os seres humanos possuem o mesmo corpo, até que ela perceba a diferença sexual. Diante da diferenciação, a menina fantasia que falta algo em seu corpo - o falo - e, decepcionada, culpabiliza inconscientemente sua mãe por tê-la gerado faltante como ela.

Freud (1932/2006) intentou explicar que para o menino a castração é algo que o faz abandonar a fase edípica, enquanto que para a menina a castração é o que proporciona o ingresso no Complexo de Édipo. Portanto, a partir dessa descoberta e apoderada de decepção, a menina esquiva-se da mãe com hostilidade por ser faltante como ela e, vivendo a nostalgia de não possuir o falo, volta-se para o pai, esperando que este lhe dê o objeto que ela não possui e tencionando encontrar uma zona segura e de apaziguamento na figura paterna (FREUD, 1932/2006).

Embora o momento de afastamento da mãe como primeiro objeto de amor seja superado pela menina, o ressentimento direcionado à figura materna não é completamente esquecido, visto que a mulher vivencia em alguns momentos da vida uma posição reivindicadora em relação à mãe.

A menina não passa pela negação derivada da mãe sem tentar algum tipo de compensação. Na fase edípica a filha se direciona à figura paterna quando faz a troca de objeto de amor (FREUD, 1932/2006). Primeiramente esta pede ao pai o objeto - falo -, que é negado. Depois da negação a menina desliza numa equação simbólica entre pênis-bebê, carregando o desejo - que é fantasioso - de presentear o pai com um bebê. Algo que também é negado. Prontamente, Freud oferece três saídas para o Édipo da menina: a cessação de sua vida sexual abandonando a sexualidade, parte feminina e parte masculina; a fantasia de ser um homem e reter a masculinidade que tanto almeja; ou o terceiro caminho, acolhendo inconscientemente a atitude feminina "normal" final, que significa reconhecer o pai como objeto e encontrar o caminho para a forma feminina do Complexo de Édipo. Freud (1932/2006) também inclui a maternidade como uma saída para a mulher, a solução para o desejo de possuir o falo-bebê. A partir dessas resoluções, pode-se perceber que todos os caminhos observados pelo autor incluem a mulher no campo da toda fálica. Conclui-se também que a consequência que se estrutura a partir do Édipo será a angustia de castração 
no menino e a fantasia de castração da menina. No entanto, menino e menina recebem uma identificação viril do pai ao saírem do Édipo, mas, diferente do menino, a menina terá que continuar a procurar uma identificação feminina.

Procurando compreender o afastamento que ocorre entre mãe e filha, Freud (1932/2006) constatou que o distanciamento não atua como uma mera mudança de objeto, mas algo além. Uma via para a feminilidade se abre após a superação de uma relação préedipiana vivida com sofrimento e é preciso que a menina reconheça a castração e faça a mudança de objeto para o pai. Porém, mantém-se um ressentimento vivido pela menina em relação à mãe -, que é desconhecido pelo menino que vive a contínua angústia da castração.

Algo que não era compreendido anteriormente, segundo Freud (1932/2006), é que o Complexo de Édipo acobertava a situação pré-edipiana da menina, ela se mantinha obscura e não percebia sua importância no desenvolvimento da sua própria feminilidade, ou seja, a fase edipiana é resultado de um duradouro momento de sentimentos ambivalentes direcionados à mãe. Logo, o processo de separação da mãe deixa um resto que não se inscreve para a menina e que a acompanhará, muitas vezes causando sofrimento.

Segundo Freud (1932/2006), a escolha por um parceiro amoroso, para algumas mulheres, passa a ter um significado quando é percebido que a mulher escolhe um parceiro com características da figura paterna, porém, repete com este o seu mau relacionamento com a mãe. $\mathrm{O}$ autor explica que isso acontece devido à intensidade do relacionamento com a mãe na fase pré-edipiana e a relação com o pai ter sido construída a partir do complexo de castração. Freud (1932/2006) nunca propôs responder por meio da teoria psicanalítica o que é uma mulher, pois responder a isto seria da ordem do impossível, mas tentou compreender o caminho que esta percorre desde a infância para tornar-se mulher e as escolhas que faz. Por que, então, a menina se separa da mãe levando consigo tanta hostilidade?

Com a dificuldade que a filha apresenta em fazer esse distanciamento, Freud (1932/2006) previa uma catástrofe no decorrer da vida desta por estar quase sempre dependente do amor da mãe. Mesmo que consiga fazer o movimento de afastamento, a mulher nunca ficará permanentemente protegida das consequências da fase pré-edipiana, mesmo que uma via para a feminilidade tenha sido descoberta por esta. Freud revela que o ressentimento da filha em direção à mãe é necessário para haver a separação, contudo, ele não pacifica a relação entre ambas, algo que seria outro caminho a ser trilhado pela mulher.

A entrada do pai na díade mãe-criança faz com que a criança tenha que sair da posição de ser o que falta à mãe - até então ela está submissa ao desejo materno, mas o outro paterno instaura a lei do incesto, ou seja, o pai, em sua intervenção simbólica, nomeia o desejo enigmático da mãe para a criança: esse desejo é o falo (ZALCBERG, 2003). No entanto, em sua função fálica, o pai nomeia o desejo da mãe e liberta a criança de uma 
posição alienante, e faz com que ela se depare com uma questão do seu próprio ser, visto que deixa de ser o falo para a mãe. Essa função feita pelo outro paterno é o que Lacan (1957/1958) chama de metáfora paterna - o que precisa acontecer para que a criança não fique presa ao mundo alienante dos desejos e significações da mãe. Portanto, o pai opera como um significante que substitui o primeiro significante introduzido na simbolização mãe-criança, que seria o da mãe. Por conseguinte, a função do pai só tem efeito se o Outro materno, que até então se posiciona como o tesouro dos significantes para a criança, também se apresentar marcado pela falta. Em seguida a criança descobrirá que aquele Outro não contém todos os significantes, bem como não pode atender a todas as suas demandas. Segundo Zalcberg (2003), é como o Outro materno terá que se revelar para criança: submetido à castração.

Se todo o processo da metáfora paterna acontecer, a criança abandona a condição de completude que, embora ilusória, era a única proporcionada pela alienação com a mãe. A partir disso ela se depara com a identificação viril que é recebida tanto pelo menino quanto pela menina na saída do Complexo de Édipo, e isso faz com que a criança encontre um lugar simbólico como sujeito desejante. Lacan (1957-1958) explica que para descolar a criança sujeita ao desejo materno é preciso que o Outro paterno entre com esse traço de identificação que será desenvolvido mais tarde na vida sujeito. Esse traço mínimo muitas vezes é suficiente para que o menino trilhe sua própria identidade, mas não é o que acontece para a menina, e por isso é dito que ela ainda terá que continuar a sua busca por uma identificação como mulher.

\section{Sobre dois recortes clínicos}

Tal qual Guimarães e Bento:

(...) o "Estudo de Caso" em psicanálise está intimamente ligado à experiência clínica. Primeiramente acontece o atendimento clínico e, em seguida, a construção do sentido daquilo que ocorrera na clínica do caso. Assim, a teoria psicanalítica vai se construindo seguindo o caminho do pathos dos pacientes (GUIMARÃES; BENTO, 2008, p.92).

\section{Um presente para a mãe}

Para algumas mulheres a busca por uma identificação de caráter feminino motiva o início de um processo analítico a partir do qual é possível observar o ressurgimento do vínculo arcaico com a mãe. Diante disso, durante uma sessão de análise, uma paciente se 
expressou da seguinte forma: "acho que meu problema é a criança que eu fui, ainda dependo muito e me importo com as opiniões da minha mãe, igual quando eu era criança. Sempre fico preocupada em como ela está vivendo, se está bem ou não" (SIC). Esse recorte ilustra o início da análise de uma paciente que vive um momento delicado e sofre crises de ansiedade. A paciente relata que durante a infância se posicionava como alguém que estava sempre ao lado da mãe, mas, enquanto mulher adulta sente que ainda precisa atender a todas as supostas demandas da mãe. Ela exemplifica essa questão contando sobre a entrada do filho na creche: "tenho tido dificuldade para fazer a adaptação do meu filho na escola, ele chora muito, ficou doente várias vezes nessas últimas semanas” (SIC). Quando questionada sobre a dificuldade em deixar o filho na escola, a mãe da paciente entra no contexto da história: "minha mãe disse que pode continuar cuidando do meu filho, disse que ele não precisa ficar sofrendo e adoecendo por causa da escolinha, mas eu sei que a escola vai ser boa para o desenvolvimento dele, então não sei o que dizer para ela" (SIC). Nesse momento a paciente entra em uma dimensão que não envolve somente ela e seu filho, mas também uma demanda da mãe e a necessidade de correspondê-la, de deixar seu filho com ela, realizando o desejo de lhe presentear.

Segundo Zalcberg (2003), um dia a menina foi o objeto que satisfazia a mãe, tendo um lugar no desejo desse Outro materno. Mas ao abandonar essa posição de completude, que corresponde a nada menos que uma fantasia de completude materna, a menina terá que lidar com uma questão sobre si mesma enquanto mulher. Contudo, ao sair dessa posição, ela passa a desconhecer o seu lugar no desejo do Outro e a necessidade de encontrar um lugar no desejo da mãe às vezes se manifesta quando a filha também se torna mãe. Zalcberg (2003) explica que a mulher pode querer oferecer o filho como um presente imaginário - para a mãe. Não sem razão, a paciente do fragmento citado acima tem dificuldade em dizer para a mãe que não quer mais deixar o filho sob seus cuidados. A paciente relata: "não sei dizer não para ela, eu sei que meu filho acaba sendo uma distração para a cabeça dela e para ela não pensar tanto nas brigas que ela tem com o meu pai” (SIC).

Além da questão com o filho, há o sintoma de ansiedade, crises que são narradas com sofrimento pela paciente. Mas afinal, o que essas crises vividas com tanta angústia revelam sobre o seu ser? Em função do quê elas apareceram? A dificuldade em fazer a separação da mãe é exemplificada com várias situações do dia-a-dia da paciente, seja com a entrada do filho na escola ou na tentativa de livrar a mãe do sofrido casamento com o pai, este visto como um "homem ruim". Em consequência, há uma fantasia que passa a ser desvendada nas sessões: uma mãe que sofre e precisa ser ajudada. Diante disso, a paciente, por sua vez, se sente responsável por amenizar o sofrimento da mãe, experimentando essa condição alienada no campo do desejo do Outro materno e sendo sufocada por isso, e não pelas suas crises, que, na verdade funcionam como um recurso a favor da separação do 
gozo materno com o qual a paciente ainda não consegue lidar. Nesse caso, o corte simbólico feito pela função paterna se revela enfraquecido. A paciente reluta ao se deparar com outros objetos de desejo e também de continuar a ocupar esse lugar mortífero de objeto de desejo da mãe. As crises de ansiedade que anteriormente pareciam ser apenas um sintoma sem sentido, passam a ser questionadas a partir dessa relação entre a paciente, o pai e a mãe.

As demandas da filha em direção à mãe funcionam como um jogo infantil que parece estar presente na vida de muitas mulheres adultas. Zalcberg (2003) esclarece que a demanda nunca pode ser completamente satisfeita, diferente da necessidade que, mesmo sempre inscrita no desejo, pode ser atendida. Isso acontece porque a demanda não funciona como a busca de um objeto que tenha valor pela substância ou qualidade, mas sim porque se trata de uma demanda de amor:

A impossibilidade de poder ser satisfeita por um objeto ofertado faz com que demanda (de amor) a um outro estruture profundamente o inconsciente do ser humano, determinando sua persistência ao longo da vida do sujeito. É o que explica a necessidade que o sujeito tem de sempre procurar um outro ao qual demandar, à espera de que sua demanda de amor seja atendida (ZALCBERG, 2003, p. 58).

Algumas mulheres permanecem para sempre cativas ao amor da mãe, buscando satisfazer as demandas maternas e esperando que as demandas pessoais dirigidas à mãe também sejam satisfeitas. De acordo com Zalcberg (2003), isso está articulado com a demanda que acompanha a mulher durante a sua vida, que é encontrar uma resposta que ofereça substância ao seu ser, de forma que a busca interminável associe-se a uma garantia de sua existência, frente à dificuldade de construir a sua identidade.

\section{A menina da mãe}

Uma jovem mulher em análise relata que sempre vivenciou a relação com a mãe de forma confusa e que se sentia abandonada por ela. $\mathrm{O}$ discurso da mãe era de que precisava dar atenção à problemática irmã mais nova, algo que fez com que a paciente experimentasse estados depressivos quando criança, sentindo-se ignorada por todos da casa. A confusão também ocorria quando a paciente ouvia as queixas da mãe sobre o pai "seu pai não presta, os homens não prestam, não chegue perto dos homens", o que provocou uma alternativa de resolução durante a adolescência - a paciente ingressa em um convento. Contudo, o projeto não é levado adiante, pois a paciente percebe não ter vocação e entende 
que seguir aquela doutrina seria apenas uma fuga para as questões que a incomodavam. A paciente, então, decide voltar para casa.

Mas a dúvida sobre se aproximar ou não dos homens permanecia nas reflexões da paciente e o significante "ignorada" também estava presente em suas relações amorosas desde muito cedo. Os meninos da escola, por exemplo, a ignoravam, assim como as colegas e a irmã mais velha, que anos mais tarde chegou a admitir isso para a paciente em forma de arrependimento. $\mathrm{O}$ discurso da jovem mulher também revela uma mãe que não cede um lugar para a ela nem mesmo no que diz respeito aos afazeres da casa: "você não sabe fazer as coisas direito, vou chamar a sua irmã - mais velha -, ela é mais esperta que você’. A mãe também não se apresenta como uma mulher que ama o marido e está sempre relatando a inutilidade dele e de outros homens. Assim, a paciente também segue destituindo seu próprio parceiro: "às vezes sinto que sou mais macho que ele, ele é muito medroso".

A paciente ainda busca nas roupas um meio para se encaixar desesperadamente no desejo da mãe. Quando jovem, a mãe não podia comprar vestimentas, pois o marido não achava necessário. Essa mulher, dona de casa e sem renda alguma, acabou encontrando uma saída e começou a costurar reformar algumas roupas. A paciente se questiona em relação a isso quando relata sobre ter compulsão por comprar peças de roupa, contando que possui várias peças, algumas em excesso, mas que é algo que não consegue controlar. Observa-se, então, que por meio das compras excessivas a paciente tenta responder a uma questão antiga da mãe, com relação a sua identidade feminina. A mãe, por sua vez, reprova a atitude da filha, dizendo que esta não tem controle e se comporta como uma criança. A paciente, então, revela sua indignação: “eu comprei as roupas com o meu dinheiro, só eu sei o quanto trabalhei para conseguir isso e não ter que pedir mais coisas a ela".

Conforme estudos de Zalcberg (2003) a menina tem a necessidade de encontrar um lugar para ela no desejo da mãe, buscando oferecer algo a esta. No recorte ilustrado acima, a paciente busca encontrar um lugar no Outro por meio do que veste e experimenta isso com angústia, dizendo que a mãe nunca está satisfeita com ela. Zalcberg (2003) menciona também que quanto mais ausente está o olhar da mãe em direção à mulher, mais ainda a mulher demanda a presença da mãe.

Por fim, quando criança, a paciente tinha todos os seus brinquedos destruídos pela irmã mais nova e sentia-se injustiçada, pois os pais priorizavam as vontades da caçula. Ela recorda que quando conquistou seu primeiro emprego, aos 18 anos, usou o primeiro salário para comprar bonecas, e as guarda até hoje no seu quarto, repleto delas. No discurso dos familiares ela é tida como uma menina, aquela que se veste como uma adolescente e tem quarto de criança. Na relação com o namorado também assume uma posição infantilizada, pedindo que ele compre bonecas de presente para ela e que ele a trate como se ela fosse um bebê. Na relação amorosa ela ainda se mantém empenhada em responder a um 
dito da mãe que a encobre: "fique longe dos homens". A fantasia que ela constrói para responder a esse comando é se congelar no corpo e nas falas de uma menina, aquela que possui bonecas e quer ser falada e olhada como se fosse a menina da mãe.

\section{Uma invenção singular: a fantasia}

Nos casos citados anteriormente, ocorre uma questão comum na vida de ambas as pacientes: qual é o lugar que ocupo no desejo da minha mãe? Diante disso, faz parte do processo analítico compreender qual é a fantasia que mantém essas duas mulheres em uma posição de satisfazer a demanda do Outro materno.

Segundo Nascimento (2010), o afastamento do Outro materno, produzido pelo processo de separação, coincide com a "travessia da fantasia". O autor explica que a fantasia se organiza como uma defesa contra o real, e para que o encontro entre o sujeito e o real seja tolerável, a fantasia se comporta como uma espécie de tela que tem a função de mascarar o real, amenizando o insuportável desse encontro. Isso nada mais é do que a própria castração do sujeito. A falta do objeto de satisfação encontrado no corpo da mãe faz com que a criança saia da posição de inércia e se torne um sujeito desejante. Nascimento (2010) comenta, inclusive, que se a mãe não se colocasse em nenhum momento como ausente, a criança permaneceria nessa posição de inércia, podendo nunca advir enquanto sujeito - implicação da alienação e castração, em que a primeira precisa acontecer para que haja o encontro com o Outro.

Tanto homem quanto mulher recorrem ao objeto da fantasia para compensar a sua falta-a-ser (ZALCBERG, 2003). A criança, posicionada como substituto fálico, possibilita que a mãe tenha acesso, na sua fantasia, ao objeto causa do seu desejo. Zalcberg (2003) explica que a mulher pode fazer dos seus filhos objeto causa de seu desejo, ou seja, a criança pode ocupar um lugar de suplementação de gozo. Mas antes de advir enquanto sujeito, a criança precisa encontrar na fantasia da mãe esse lugar imaginário. Antes do encontro com o Outro a criança precisa ter ocupado essa condição de alienado e recoberto pelo campo da fantasia da mãe. É preciso, então, que alguém dite e fale dessa criança para que ela possa advir enquanto sujeito desejante.

Nesse sentido, deve-se refletir sobre como será o destino da criança em relação ao lugar que ocupou no objeto de fantasia da mãe, e se foi ou não regulada pela função simbólica. O que as pacientes trazem para o processo analítico é o que restou dessa posição subjetiva que foi se constituindo. Zalcberg (2003) comenta sobre o efeito causado na menina ao experimentar ser parte do corpo da mãe e diz que o fato da filha não se encontrar mais identificada a esse objeto de desejo materno pode ser traduzido em sofrimento, principalmente para a menina. Logo, como relatado no início deste trabalho, a função paterna funciona justamente para regular esse gozo do Outro materno, limitado para a criança e 
Santos, F. C. W., \& Radaelli, J.

para a mãe. É esse o operador que parece estar enfraquecido na relação de ambas pacientes mencionadas anteriormente. Em alguns momentos estão fixadas ao lugar de objeto de gozo da fantasia da mãe e tentam responder desse lugar com uma invenção própria.

A pergunta que persiste é “o que ela quer de mim?”. Esta questão está presente no discurso das pacientes, as quais respondem a isso com uma invenção imaginária, ou seja, suas próprias fantasias. No primeiro recorte de análise a paciente enxerga a mãe como uma mulher que sofre com o casamento e a partir disso cria uma fantasia com o objetivo de estancar a falta da mãe. A filha não pode ver a mãe sofrer e por isso oferece seu filho, seu tempo e seus ouvidos para a mãe reclamar do marido hostil. Por estar presa a esse relacionamento com a mãe, a paciente sofre, tem crises de ansiedade e receia tanto perder a mãe que acaba se perdendo.

No segundo caso, para manter a aliança com a mãe, a paciente afasta-se da sua própria sexualidade. Ela cria a fantasia de que precisa se posicionar como uma menina, assim ela continuará identificando-se com a orientação da mãe sobre manter-se longe dos homens. A paciente, então, permanece ligada a mãe através das roupas, da voz infantilizada e dos brinquedos de infância.

Referente aos recortes e observações supracitados, conclui-se que corresponder às expectativas imaginárias da mãe resulta em um trabalho árduo para as pacientes, que acabam se identificando com a mulher que pensam ser a imagem da mulher ideal para a mãe. Segundo Zalcberg (2003) buscar a identificação baseado no que acha ser o ideal para a mãe já é algo constituído na infância. Quando é capaz, no início da gestação, a mãe elabora uma imagem idealizada da criança e, assim que nasce, esta procura identificar-se com a imagem estruturada. Com isso, a criança abriga em si o objeto (a) que representou na fantasia da mãe. Logo, esse processo é imprescindível na constituição do sujeito, porque a criança precisa ocupar esse lugar quando vem ao mundo materno, estando alienada a ele. Primeiramente a mãe idealiza para comportar a criança na sua própria falta-a-ser, vivida tanto como sujeito quanto como mulher. Em seguida, para situar a criança no registro simbólico da sua família e da sociedade. No entanto, posteriormente, a introdução da metáfora paterna vem para estruturar e nomear o objeto de desejo da mãe, para que a criança não ocupe mais este lugar. Conforme Zalcberg (2003), nesse momento estruturante para a criança, a metáfora paterna não recobre tudo, algo fica externo ao processo de simbolização e o que fica fora será chamado de "resto" - algo que se destaca e não pode ser nomeado pela metáfora paterna. "Trata-se de um objeto, mas como não tem consistência, é conhecido na teoria lacaniana como objeto pequeno a ou de forma encurtada, objeto (a)" (ZALCBERG, 2003, p.74).

É a partir dessa operação que a criança se depara com a falta, e primeiramente com a falta do Outro. A dificuldade aparece, pois a criança se constitui a partir da completude materna, ou seja, o Outro materno, para a criança, não apresenta falhas. Zalcberg 
(2003) verifica que a mulher terá ainda mais dificuldade em reconhecer a falta do Outro materno. Além da impossibilidade de reconhecer que este Outro não existe como fora imaginado, a mulher também reluta em reconhecer a falta-a-ser da mãe como mulher, aquela que não possui um significante especificamente feminino representante do seu sexo. Articulado a isso está o medo do apagamento do seu próprio ser, pois ela está a todo o momento demandando uma resposta sobre quem ela é, e a demanda geralmente se mantém direcionada à mãe.

A fantasia é, portanto, algo que se elabora na constituição do sujeito. É a partir do complexo de castração que o sujeito é introduzido no mundo dos seres falantes. No entanto, para que isso se consolide, tanto homem quanto mulher devem renunciar a uma parte de gozo que o corpo proporciona para os seres. É por meio da perda do chamado "gozo do ser" que o sujeito pode ter acesso a um gozo permitido, que é o gozo sexual (ZALCBERG, 2003) Contudo, o sujeito não deixará isso se apagar, pois ele sempre buscará ter acesso a algo desse gozo perdido. E para isso o sujeito faz uma invenção, que é a fantasia. Uma “tentativa de recuperação de gozo é o que o objeto (a) causa do desejo, na fantasia, significa, e, por isso, Lacan chamará o objeto (a) de objeto mais-de-gozar” (ZALCBERG, 2003, p.121). Assim, de um lado encontra-se a representação do sujeito, visto como sujeito barrado e atravessado pelos significantes; e de outro está o objeto (a), que é a versão da satisfação pulsional, do gozo.

O objeto falta, e o sujeito vai justamente homologar esta perda do objeto formando uma fantasia. Assim, nesse primeiro momento, a fantasia não é mais do que a representação imaginária do objeto perdido. Esse objeto que serve de suporte à fantasia é então o objeto que causa e coloca em movimento o desejo do sujeito. O objeto da fantasia é o objeto (a), o que é bem indicado por seu matema: $\$ \triangleright$ a (NASCIMENTO, 2010, p.08).

Visto isso, é por intermédio da fantasia que o sujeito pode construir um mundo em torno do gozo, mesmo não podendo atingí-lo, já que está impedido de ter acesso ao gozo do ser. No entanto, a fantasia não se trata apenas do processo de constituição do sujeito, sendo também o núcleo dos desejos atuais do sujeito. Nascimento (2010) explica que a fantasia possibilita que a realidade do sujeito seja atravessada pelo desejo, funcionando como uma moldura da realidade. Além disso, outra função da fantasia é organizar a realidade humana, deixando de ser apenas uma função imaginária para também ser reconhecida como função simbólica. 
Seu matema deixa entrever isso sob a forma desta barra (\$) que divide o sujeito para sempre, que é a marca de sua entrada na linguagem e seu assujeitamento a ela. Dessa maneira, a fantasia é o conceito que permite amarrar os três registros: o simbólico (representado pela barra do $\$$ ), o imaginário (pequeno a) e o real (pequeno a) (NASCIMENTO, 2010, p.08).

Verifica-se mediante aos casos relatados, como essas mulheres moldam suas realidades através da fantasia criada. É encobrindo com véu fantasmático que elas interpretam a própria realidade. As fantasias são vivenciadas consciente e inconscientemente e elas percebem que os relatos sobre a questão fantasmática são recorrentes em suas sessões de análise, despertando muitas emoções. Contudo, o que escapa é o sentido desses eventos. Mesmo ocorrendo em diversos momentos da vida e independente da vontade, a fantasia sempre reaparece como algo enigmático do seu ser.

\section{Considerações finais}

O presente estudo propôs analisar uma a problemática relação que pode ocorrer entre mãe e filha, de forma a compreender o significado das fantasias construídas pelas pacientes para responder a pergunta imaginária "O que o Outro materno quer de mim?". Os recortes clínicos das pacientes foram avaliados a fim de apresentar detalhes da elaboração de suas fantasias. Também foi possível retomar conhecimentos da teoria psicanalítica, comentando o conceito edipiano da obra de Freud, Lacan e outros comentadores.

Diante das questões abordadas no texto, consideraram-se alguns pontos como, por exemplo, o caminho percorrido pela filha para tentar se identificar e se encaixar no desejo da mãe. Conclui-se que por meio de tentativas a filha entra em um emaranhado em que estão as suas questões enquanto filha e também enquanto mulher. Consequentemente, por estar sempre empenhada em encontrar seu lugar no campo do desejo da mãe, ela vai se extinguindo enquanto sujeito. Sua feminilidade, que poderia ser inventada e constituída como única, se resume a uma eterna ausência de si mesma.

Embora essa situação seja encarada por muitas filhas como uma questão insolucionável, é possível vislumbrar um processo de criação feminina. Para Zalcberg (2003) a falta de identificação feminina da filha pode ser compensada quando a mãe acolhe o corpo da filha como corpo de mulher. Ou seja, se for possível, a mãe cria algo dessa identidade feminina que é única para cada mulher. São as palavras da mãe que encobrem a menina, de forma simbólica, pela falta imaginária que marca o corpo da filha. Nesse sentido, as palavras da mãe podem ser tanto acolhedoras quanto mal ditas. 
Enfim, com esta pesquisa foi possível perceber que em alguns momentos a filha se posiciona como aquela que espera que a mãe abra uma via de acesso para a feminilidade. E, se mortificando em uma posição alienante em relação à mãe, ambas acabam buscando uma na outra a resposta sobre o seu ser, sendo que ele inexiste.

Logo, a função do processo edípico é deixar sua marca delimitadora na filha e na mãe, não tendo o poder de separar completamente os dois sujeitos. Zalcberg (2003) aponta que há algo entre mãe e filha que permanece inseparável, algo que a metáfora paterna não alcança, e acabará como um "resto", que fica fora de simbolização. É por isso que em muitos momentos a filha estará à espera de um significante especificamente feminino que a defina enquanto mulher.

Da experiência analítica é possível extrair algumas questões sobre a mulher que se apresentam no formato de um nó. Com a análise procura-se fazer uma distinção: o corpo da filha e o corpo da mãe. Reside no discurso da filha uma ligação com a mãe que ilusoriamente parece possibilitar uma transmissão do que é ser uma mulher. Cabe ao processo analítico fazer o luto da posição de menina da mãe para tornar-se mulher e esboçar um caminho singular em direção a algo de feminino em si mesma.

Nesse processo de afastamento, algumas mudanças na relação entre ambas podem acontecer. Ocorrem momentos de ódio e hostilidade, e outros de amor e compreensão. O momento de separação, portanto, não é um caminho simples a ser trilhado. Uma separação possibilita que haja distinção entre corpos e também que se encontre uma proximidade que não seja sufocante.

\section{Referências}

Freud, S. Três ensaios sobre a teoria da sexualidade (1905). In Edição standard brasileira das Obras Psicológicas Completas de Sigmund Freud. Rio de Janeiro: Imago, 2006, v. VII, p. $119-218$.

Freud, S. Fragmento da análise de um caso de histeria (1905). In Edição standard brasileira das Obras Psicológicas Completas de Sigmund Freud. Rio de Janeiro: Imago, 2006, v. VII, p.15-116.

Freud, S. O Ego e o Id e outros trabalhos (1923). In Edição standard brasileira das Obras Psicológicas Completas de Sigmund Freud. Rio de Janeiro: Imago, 2006, v. XIX, p. 15-80. Freud, S. A organização genital infantil (1923). In Edição standard brasileira das Obras Psicológicas Completas de Sigmund Freud. Rio de Janeiro: Imago, 2006, v. XIX, p.15716. 
Freud, S. A dissolução do Complexo de Édipo (1924). In Edição standard brasileira das Obras Psicológicas Completas de Sigmund Freud. Rio de Janeiro: Imago, 2006, v. XIX, p. 189-199.

Freud, S. Sexualidade feminina (1931). In Edição standard brasileira das Obras Psicológicas Completas de Sigmund Freud. Rio de Janeiro: Imago, 2006, v. XXI, p. 231-251.

Freud, S. Feminilidade (1932). In Edição standard brasileira das Obras Psicológicas Completas de Sigmund Freud. Rio de Janeiro: Imago, 2006, v. XXII, p. 113-134.

Guimarães, R. M; Bento, V. E. S. O método do "estudo de caso" em psicanálise. PUCRS, Porto Alegre, v. 39, n. 1, p. 91-99, 2008.

Lacan, J. A metáfora paterna (1957/1958). In: O Seminário, Livro 5. Rio de Janeiro: J. Zahar, 1999, p. 166-184.

Lacan, J. O aturdito (1972). In: Outros Escritos. Rio de Janeiro: J. Zahar, 2003, p. 448497.

Nascimento, M. B. Alienação, separação e travessia da fantasia. Opção Lacaniana online nova série. Ano 01, n. 01, 2010.

Zalcberg, M. A Relação Mãe e Filha. Rio de Janeiro: Editora Campus, 2003.

Zalcberg, M. A Nostalgia a Ter: A Dor da Feminilidade, Psicologia Clínica, Publicação do

Departamento de Psicologia da PUC, Rio de Janeiro, v. 16, n. 16, 2004. 